Economics Development Analysis Journal

\title{
Strategi Pengembangan Nelayan Tangkap PPP Bajomulyo Kabupaten Pati
}

\section{Galih Puspasari ${ }^{1 凶}$}

Jurusan Ekonomi Pembangunan, Fakultas Ekonomi, Universitas Negeri Semarang

\section{Info Artikel}

Sejarah Artikel:

Diterima Oktober 2016

Disetujui Desember 2017

Dipublikasikan Februari 2017

\section{Keywords:}

GDP, fishing, constraints, strategy development

\begin{abstract}
Abstrak
Pada negara maju, sektor industri dan jasa merupakan sektor yang berperan cukup besar dalam pendapatan nasionalnya dan juga dalam penyediaan kesempatan kerja, sementara bagi negara negara berkembang sektor pertanian yang memberikan peranan besar, baik terhadap pendapatan maupun penyediaan kesempatan kerja. Salah satu sub sektor pada sektor pertanian penyumbang PDRB adalah sub sektor perikanan. Permasalahan dalam penelitian ini adalah faktor - faktor internal dan eksternal yang dihadapi dalam pengembangan nelayan tangkap PPP Bajomulyo Kabupaten Pati. Populasi dalam penelitian ini sebanyak 395 orang nelayan di PPP Bajomulyo Juwanan Kabupaten Pati, sedangkan sampel yang diambil dalam penelitian ini sebanyak 28 orang nelayan, diambil dengan teknik area random sampling. Metode analisis dalam penelitian ini menggunakan analisis deskriptif statistik dan analisis SWOT. Strategi pengembangan nelayan tangkap PPP Bajomulyo Kabupaten Pati adalah dengan otonomi daerah pemerintah semakin menggali potensi sumber daya yang tersedia yang dimiliki oleh sub sektor perikanan tangkap PPP Bajomulyo Juwana dan mengoptimalkan pengelolaan PPP Bajomulyo Juwana.
\end{abstract}

\section{Abstract}

In developed countries, industry and services sector is a sector that plays quite large in the national income and also in the provision of employment opportunities, while for developing countries the agricultural sector which gives a major role, both on the revenue and the provision of employment opportunities. One sub - sector to the agricultural sector contributor to the GDP is the fisheries sub-sector. Problems in this study are the internal factors and external facing fisherman catch. Population in this study as many as 395 people, while the samples taken in this study were 28 people, taken with the technique of random sampling area. The analytical method used is descriptive statistical analysis and SWOT analysis. The development strategy of fishermen fishing in PPP Bajomulyo Juwana Regency, among others by means of local autonomy governments are increasingly exploring the potential of available resources owned by sub - sector of fisheries PPP Bajomulyo Juwana and optimize the management of PPP Bajomulyo Juwana.

(C) 2017 Universitas Negeri Semarang

\footnotetext{
${ }^{\circledR}$ Alamat korespondensi:

Ruang Jurnal Gedung L FE UNNES, Sekaran Gunungpati

Semarang, 50229, Indonesia

E-mail: osin.moon@gmail.com
}

ISSN 2252-6965 


\section{PENDAHULUAN}

Pembangunan ekonomi daerah adalah suatu proses pemerintah daerah dan seluruh komponen masyarakat mengelola berbagai sumber daya yang ada dan membentuk suatu pola kemitraan untuk menciptakan suatu lapangan pekerjaan baru dan merangsang perkembangan kegiatan ekonomi dalam daerah tersebut. Tentu saja makna pembangunan daerah tersebut amat tergantung dari masalah fundamental yang dihadapi oleh daerah itu (Kuncoro, Mudrajad, 2004: 110).

Menurut Lincolin Arsyad (2005: 109) tujuan utama pembangunan ekonomi daerah adalah untuk meningkatkan kesejahteraan masyarakat dengan cara peningkatan jumlah dan jenis peluang kerja untuk masyarakat setempat.

Peranan sektor kelautan dan perikanan dalam pembangunan nasional terutama adalah mendorong pertumbuhan agroindustri melalui penyediaan bahan baku, meningkatkan devisa melalui peningkatan ekspor hasil produk kelautan dan perikanan, meningkatkan kesempatan kerja, meningkatkan pendapatan dan kesejahteraan petani atau nelayan serta menunjang pembangunan nasional. Salah satu potensi sumber daya perikanan yang telah memberikan kontribusi cukup signifikan bagi perekonomian Kabupaten Pati adalah sub sektor perikanan tangkap. Adanya Pelabuhan Perikanan Pantai Bajomulyo Juwana mendorong aktivitas perikanan tangkap lebih teratur dan terarah. PPP Bajomulyo Juwana mempunyai potensi untuk dikembangkan menjadi PPP yang lebih baik lagi dilihat dari potensi sumber daya perikanan yang besar. Kabupaten Pati mempunyai potensi yang cukup besar selain wilayahnya yang berbatasan langsung dengan Laut Jawa. Potensi sumber daya perikanan yang cukup besar tersebut memberikan keuntungan yang cukup besar pula, dengan adanya kebijakan otonomi daerah Kabupaten Pati sepenuhnya dapat mengelola sumber daya perikanan yang ada secara bertanggung jawab. Pengelolaan sumber daya perikanan diharapkan dapat mengoptimalkan pengelolaan sumber daya yang selama ini dirasakan belum optimal dan nantinya juga diharapkan dapat menjadi tumpuan perekonomian di Kabupaten Pati yang dapat digunakan sebagai sumber biaya operasional pembangunan daerah setempat. Pelabuhan Perikanan Pantai Bajomulyo Juwana menjadi salah satu tulang punggung kekuatan perekonomian di Kecamatan Juwana dengan kunjungan kapal nelayan pada tahun 2013 mencapai 17.465 buah. Hasil laut dibongkar dan dijual di TPI Bajomulyo yang memiliki nilai lelang terbesar di Kabupaten Pati hingga mencapai $96,32 \%$ dari total nilai ikan basah hasil pelelangan, bahkan pada tahun 2013 produksi ikan laut segar di PPP Bajomulyo Juwana Unit I mencapai $974.218 \mathrm{~kg}$ atau senilai 30,9 milyar rupiah dan PPP Bajomulyo Juwana Unit II mencapai $31.196 .585 \mathrm{~kg}$ atau senilai 708,26 milyar rupiah.

\section{Penelitian Terdahulu}

1. Mengutip Jurnal dari M. Ramli yang berjudul "Perkembangan dan Kontribusi Sub Sektor Perikanan terhadap PDRB Kabupaten Rokan Hilir Riau" (2013). Penelitian ini bertujuan untuk melihat perkembangan PDRB, ketenagakerjaan dan perikanan Kabupaten Rokan Hilir secara runtut waktu. Berdasarkan kurun waktu 2006 hingga 2010, sektor perikanan memberikan kontribusi 21,62\%. Dan dilihat kontribusinya dalam sesama sektor pertanian, sub sektor perikanan adalah penyumbang terbesar (41\%) diantara sub sektor lainnya (tanaman pangan \& hotikultura, tanaman perkebunan, peternakan \& kehutanan). Usaha perikanan di Kabupaten Rokan Hilir didominasi oleh perikanan tangkap di laut. Produksi perikanan pada tahun 2010 tercatat 59.808,43 ton, naik dari produksi tahun - tahun 
sebelumnya. Peningkatan produksi terjadi terutama pada produksi perikanan budidaya.

2. Mengutip Jurnal dari Ilhamsyah, Effendi P Sitanggang dan Johnny Budiman yang berjudul "Kontribusi Hasil Perikanan Laut terhadap PDRB Kabupaten Raja Ampat Provinsi Papua Barat" (2014). Penelitian ini bertujuan untuk mengetahui seberapa besar hasil PDRB Kabupaten Raja Ampat dan PDRB Provinsi Papua Barat. Dengan PDRB Migas, PDRB Kabupaten Raja Ampat berkontribusi 3,73\% per tahun (ADHB) dan 4,99\% per tahun (ADHK) terhadap PDRB Papua Barat selama periode 2009-2013, sedangkan tanpa PDRB Migas, PDRB Kabupaten Raja Ampat berkontribusi 3,87\% per tahun (ADHB) dan 4,40\% per tahun (ADHK) terhadap PDRB Papua Barat selama periode tersebut; Dengan PDRB Migas, sub sektor perikanan berkontribusi $23,02 \%$ per tahun (ADHB) dan 26,30\% per tahun (ADHK) terhadap PDRB Kabupaten Raja Ampat selama periode tersebut; sementara tanpa PDRB Migas, kontribusi sub sektor perikanan ini masing - masing $42,70 \%$ per tahun (ADHB) dan $49,71 \%$ per tahun (ADHK). Dengan dan tanpa PDRB Migas, sub sektor perikanan Kabupaten Raja Ampat berkontribusi $14,45 \%$ per tahun (ADHB) dan $17,93 \%$ per tahun (ADHK) terhadap sub sektor perikanan Papua Barat; Kontribusi hasil laut terhadap PDRB sub sektor perikanan Kabupaten Raja Ampat selama periode tersebut $0,55 \%$ per tahun dihitung (ADHB) dan $0,55 \%$ per tahun (ADHK).

\section{METODE PENELITIAN}

Jenis penelitian ini menggunakan penelitian pendekatan deskriptif analisis dengan pendekatan kualitatif. Pendekatan deskriptif analisis dengan pendekatan kualitatif dalam penelitian ini yaitu dengan cara memberikan gambaran mengenai data atau kejadian berdasarkan fakta - fakta yang tampak pada situasi yang diselidiki peneliti dan objek yang diteliti terpisah, proses penelitian yang dilakukan melalui pengukuran dengan alat yang baku matriks SWOT. Jenis data yang digunakan dalam penelitian adalah data primer dan data sekunder. Metode pengumpulan data yang digunakan dalam penelitian ini adalah metode observasi dan metode kuesioner.

Proses pengumpulan data dilakukan dengan dua cara:

1. Metode Observasi

Teknik ini dilakukan dengan melakukan survei secara langsung terhadap aktivitas nelayan tangkap di PPP Bajomulyo Kecamatan Juwana. Dengan teknik ini, penulis dapat melihat kegiatan dan proses menangkap ikan secara langsung.

\section{Kuesioner}

Dari pengumpulan data kuesioner diperoleh data primer, yaitu data yang didapat langsung dari responden. Data yang diperoleh berupa jawaban responden atas pertanyaan yang diajukan berdasarkan pertanyaan dengan menjawab pertanyaan dengan menulis jawaban pada lembar kuesioner dan pilihan rating untuk analisis SWOT. Dalam penelitian ini peneliti memberikan kuesioner untuk diisi responden yaitu nelayan tangkap di PPP Bajomulyo Kecamatan Juwana.

\section{HASIL DAN PEMBAHASAN}

Kondisi perikanan tangkap PPP Bajomulyo Juwana Kabupaten Pati dilihat dari umur responden mayoritas berusia 41 55 tahun, tingkat pendidikan sebagian besar nelayan tamat SD, jenis ikan yang ditangkap disesuaikan dengan alat tangkap yang dimiliki nelayan, alat tangkap yang digunakan berupa jaring angkat, purse seine, jaring cumi dan cantrang, sedangkan permodalan mayoritas nelayan menggunakan modal sendiri, luas wilayah melaut nelayan sebagian besar sejauh 3 mil, kepemilikan kapal mayoritas milik nelayan 
sendiri, pemasaran hasil produksi ikan di PPP Bajomulyo Juwana sebagian besar dijual sendiri.

Faktor - faktor Yang Mempengaruhi Perkembangan Nelayan Tangkap

\section{Kendala Internal}

Jenis ikan, dari 80 responden $31,25 \%$ mengalami kendala pada jenis ikan, umumnya nelayan mengalami kendala pada ketersediaan jenis ikan yang ada. Alat tangkap, dari 80 responden $33,75 \%$ memilih alat tangkap tradisional dan $66,25 \%$ memilih alat tangkap modern mengalami kendala pada alat tangkapnya. Pemasaran, dari 80 responden $100 \%$ setuju jika pemasaran menjadi kendala karena harga ikan dipasaran tidak stabil dan selalu berubah ubah sehingga harga tidak bisa diprediksi. Modal, dari 80 responden $70 \%$ nelayan memakai modal sendiri, sehingga tak jarang mereka lebih memilih sistem pemasaran dengan cara dijual sendiri karena lebih cepat mendapatkan keuntungan dan mengembalikan modal yang sudah mereka keluarkan.

\section{Kendala Eksternal}

Lokasi geografis PPP Bajomulyo Juwana kurang strategis dan kondisi jalan yang kurang memadai sehingga proses produksi berjalan lambat dan biaya transportasi meningkat, dari 80 responden hanya $3,75 \%$ saja yang mengalami kendala mengenai lokasi geografis PPP Bajomulyo Juwana yang kurang strategis dan kondisi jalan yang kurang memadai serta biaya tranportasi yang terus meningkat. Kondisi alam yang datang pada waktu yang tidak terduga sehingga mengganggu produktivitas nelayan, dari 80 responden $100 \%$ nelayan setuju jika kondisi alam/ cuaca menjadi kendala yang mengganggu kegiatan produktivitas nelayan. Munculnya hasil tangkapan dari wilayah lain, dari 80 responden $2,5 \%$ nelayan setuju jika munculnya hasil tangkapan dari wilayah lain menjadi kendala karena akan menurunkan permintaan ikan dan ikan yang diperoleh nelayan harus bersaing harga dengan ikan dari wilayah lain. Menurunnya daya dukung lingkungan, dari 80 responden 7,5\% nelayan setuju jika menurunnya daya dukung lingkungan menjadi kendala karena hasil produksi nelayan yang diperoleh bergantung pada lingkungan nelayan.

\section{Identifikasi Faktor-Faktor Internal Dan Eksternal}

Tahap pertama dalam analisis SWOT adalah melakukan identifikasi terhadap faktor-faktor internal dan eksternal di lingkungan Pemerintah Daerah Kecamatan Juwana yang dianggap berpengaruh secara positif maupun secara negatif dalam merencanakan dan melaksanakan pembangunan daerah. Dengan melakukan pembandingan faktor eksternal peluang (opportunities) dan ancaman (treats) dengan faktor internal kekuatan (strength) dan kelemahan (weakness), untuk menghasilkan analisis yang tepat. Tahap ini sangat penting karena hasil dari identifikasi ini akan menjadi dasar untuk kegiatan analisis berikutnya.

Berdasarkan hasil penelitian, faktor internal kekuatan adalah luas wilayah memiliki skor 0,38. Sumber daya alam memiliki skor 0,35 . Tingkat keamanan dari hantaman gelombang memiliki skor 0,30. Jarak antar pasar memiliki skor 0,29. Dukungan pemerintah memiliki skor 0,28. Secara umum jumlah pembobotan skor pada aspek kekuatan sebesar 1,60. Point luas wilayah memiliki skor pembobotan tertinggi dengan nilai 0,38. Kesimpulannya luas wilayah merupakan point kekuatan untuk nelayan tangkap, karenanya akan lebih mudah untuk memproduksi hasil tangkapan jika tidak ada hambatan pada luas wilayah.

Berdasarkan hasil penelitian, pada faktor internal kelemahan adalah sumber daya manusia memiliki skor 0,35 . kualitas ikan memiliki skor 0,27. Fasilitas memiliki skor 0,14 . Sistem sanitasi memiliki skor 0,33 . Teknologi penangkapan memiliki skor 0,13 . Secara umum jumlah pembobotan skor pada 
aspek kelemahan sebesar 1,25. Dan sumber daya manusia memiliki skor paling tertinggi sebesar 0,35. Jadi kelemahan terbesar dari nelayan tangkap adalah rendahnya sumber daya manusia yang ada.

Berdasarkan hasil penelitian, faktor eksternal peluang adalah peningkatan pendapatan nelayan memiliki skor 0,32 . Distribusi memiliki skor 0,31. Tingkat konsumsi memiliki skor 0,29 . Peningkatan mutu memiliki skor 0,26. Usaha penunjang memiliki skor 0,15. Kesimpulannya faktor eksternal peluang yang memiliki skor terbesar adalah peningkatan pendapatan nelayan. Besarnya pendapatan nelayan yang memberikan peluang bagi nelayan tangkap yang terus bertambah.

Berdasarkan hasil penelitian, faktor eksternal ancaman adalah cuaca memiliki skor 0,38. Musim ikan memiliki skor 0,35. Harga ikan memiliki skor 0,33. Ketersediaan BBM memiliki skor 0,29. Perkembangan teknologi diluar PPP memiliki skor 0,12. Secara umum jumlah pembobotan pada aspek ancaman sebesar 1. Faktor cuaca memiliki skor pembobotan tertinggi yaitu 0,38 . Kesimpulannya dapat dilihat dari bobot skor tertinggi ancaman terbesar yaitu faktor cuaca.

\section{Matriks SWOT}

Total skor faktor strategi internal

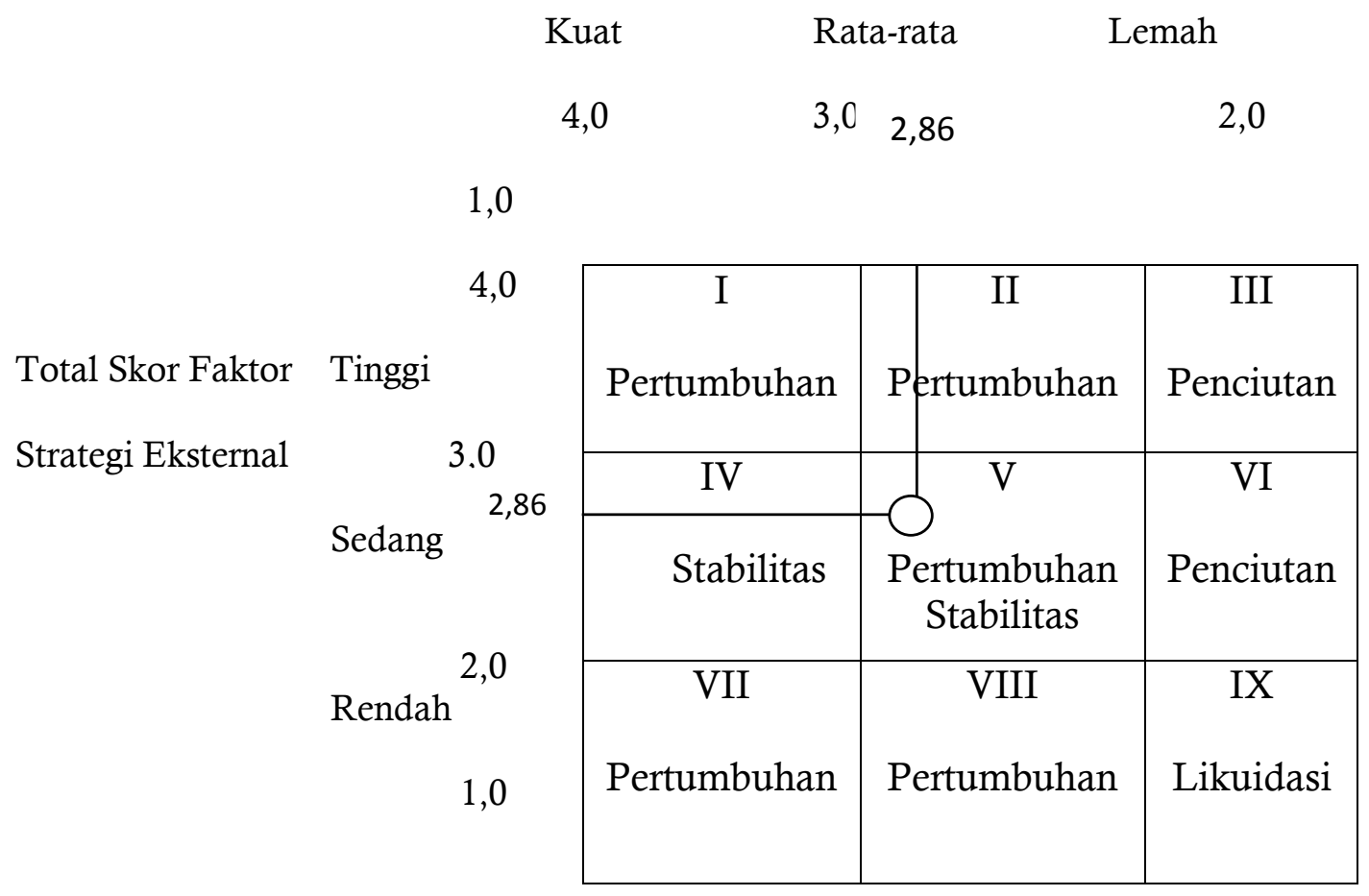

\section{Gambar 4.1 Matrik Internal Eksternal}

Sumber : Data Primer, Diolah 
Jumlah skor internal kekuatan adalah 3 dan kelemahan 2,6. Sedangkan jumlah skor eksternal peluang adalah 2,8 dan ancaman 2,8. Dari total skor yang diperoleh, yaitu faktor strategis internal 0,4 dan faktor strategis eksternal 0 menunjukkan titik koordinat terletak pada daerah pertumbuhan V seperti ditunjukkan pada Gambar Internal - Eksternal Matriks (Rangkuti, 2006:42), dalam kasus ini berarti strategi pemecahan masalah harus konsentrasi melalui integrasi horizontal.

Berdasarkan analisis matrik SWOT, maka dapat diajukan beberapa strategi untuk mengembangkan nelayan tangkap PPP Bajomulyo Kabupaten Juwana. Strategi yang pertama adalah strategi SO yaitu penciptaan struktur ruang dan pola pemanfaatan wilayah wilayah yang memperhatikan upaya pemeliharaan keanekaragaman hayati baik flora maupun fauna, pengembangan sub sektor perikanan tangkap diwilayah pesisir yang berorientasi pada pengembangan sektor perikanan dan kelautan yang berkelanjutan, pemerintah memberikan kebijakan untuk mendukung sub sektor perikanan tangkap, bekerja sama dengan industri pengolahan hasil perikanan tangkap.

Strategi yang kedua adalah strategi WO yaitu meminimalkan kelemahan untuk memanfaatkan peluang. Yaitu pengembangan sumber daya manusia untuk meningkatkan kualitas hidup dengan mendistribusikan secara proporsional fasilitas - fasilitas pendukung di Kabupaten Pati, memperbaiki sistem sarana dan prasarana penunjang sub sektor perikanan tangkap agar hasil produksi ikan lebih optimal, pengembangan sistem informasi geografis dan perencanaan sebagai satu sistem yang utuh dan terpadu untuk mendukung proses perencanaan, pemanfaatan dan pengendalian ruang diwilayah Kabupaten Pati sekaligus sebagai upaya mendorong peningkatan pendapatan nelayan setempat.

Strategi yang ketiga adalah strategi ST adalah pembenahan sistem kelola di PPP, pembenahan sistem penjualan, pengembangan kerjasama antar kabupaten/ kota dengan provinsi sebagai koordinator mediasi untuk penetapan kawasan-kawasan andalan dan pengembangan ekonomi terpadu yang berbasiskan pada komoditas-komoditas unggulan sub sektor perikanan.

Strategi yang keempat adalah strategi WT yaitu strategi yang meminimalkan kelemahan dan menghindari ancaman. Sosialisasi tentang perkembangan sub sektor perikanan tangkap, otonomi daerah perlu ditingkatkan untuk pengembangan sub sektor perikanan tangkap, pengembangan kegiatankegiatan ekonomi masyarakat setempat, terutama yang ada diwilayah pesisir melalui penguatan modal dengan pembinaan (industri besar membina industri kecil dan menengah agar menguntungkan kedua belah pihak).

\section{SIMPULAN}

Berdasarkan hasil penelitian dan pembahasan, dapat diambil kesimpulan bahwa kondisi perikanan tangkap PPP Bajomulyo Juwana Kabupaten Pati dilihat dari umur responden mayoritas berusia 41 - 55 tahun, tingkat pendidikan sebagian besar nelayan tamat $\mathrm{SD}$, jenis ikan yang ditangkap disesuaikan dengan alat tangkap yang dimiliki nelayan, alat tangkap yang digunakan berupa jaring angkat, purse seine, jaring cumi dan cantrang, sedangkan permodalan mayoritas nelayan menggunakan modal sendiri, luas wilayah melaut nelayan sebagian besar sejauh 3 mil, kepemilikan kapal mayoritas milik nelayan sendiri, pemasaran hasil produksi ikan di PPP Bajomulyo Juwana sebagian besar dijual sendiri, faktor - faktor yang dihadapi dalam pengembangan nelayan tangkap antara lain faktor internal dan faktor eksternal, yang termasuk faktor internal adalah jenis ikan, alat tangkap salah satunya jaring yang digunakan sering berlubang bahkan sobek, pemasaran umumnya harga yang tidak bisa stabil, modal usaha umumnya masih menggunakan modal sendiri. Sedangkan faktor eksternal adalah lokasi geografis PPP Bajomulyo Juwana yang kurang strategis dan kondisi jalan yang kurang memadai, sebagian nelayan mengalami pada kondisi alam yang datang pada waktu yang tidak terduga, selain itu nelayan mengalami 
kendala munculnya hasil tangkapan dari wilayah lain serta menurunnya daya dukung lingkungan, strategi pengembangan nelayan tangkap PPP Bajomulyo Juwana adalah dengan potensi sumber daya yang tersedia dan kualitas ikan yang ada di PPP Bajomulyo Juwana menjalin kerjasama dengan industri pengolahan hasil perikanan tangkap, dengan otonomi daerah pemerintah semakin menggali potensi yang dimiliki oleh sub sektor perikanan tangkap PPP Bajomulyo Juwana, adanya kebijakan kebijakan yang diambil pemerintah yang lebih baik, mengembangkan sumber daya manusia sesuai dengan kemampuan yang dimiliki, menumbuh kembangkan budaya kerja dengan meningkatkan produktivitas kerja, mencukupi sarana dan prasarana, mengoptimalkan pengelolaan PPP Bajomulyo Juwana, meningkatkan sosialisasi mengenai pengembangan nelayan tangkap, membenahi akses perbankan, koperasi atau lembaga terkait lainnya dan pemerintah daerah memberikan rekomendasi untuk dapat menggerakkan sub sektor perikanan tangkap.

\section{DAFTAR PUSTAKA}

Arsyad, Lincolin. 2005. Pengantar Perencanaan dan Pembangunan Ekonomi Daerah. Edisi Kedua. Yogyakarta: BPFE.

Bertrand, Sophie., Bertrand, Arnaud., Carrasco, Renato Guevara., Gerlotto, François. 2007. Scale-Invariant Movements Of Fishermen: The Same Foraging Strategy As Natural Predators. Ecological Society of America 17 (2) pp. 331-337.

Budiman, Johnny, Ilhamsyah, dan Effendi P Sitanggang. 2014. Kontribusi Hasil Perikanan Laut terhadap PDRB Kabupaten Raja Ampat Provinsi Papua Barat. Jurnal Ekonomi.

Kuncoro, Mudrajad. 2010. Ekonomika Pembangunan : Masalah, Kebijakan, dan Politik. Jakarta: Erlangga.

Rangkuti, Freddy. 2006. Analisis SWOT Teknik Membedah Kasus Bisnis. Jakarta : Gramedia Pustaka Utama.

Ramli, M. 2013. Perkembangan dan Kontribusi Sub Sektor Perikanan terhadap PDRB Kabupaten Rokan Hilir. Skipsi.
Reilly, Kieran., O'hagan, Anne Marie., Dalton, Gordon. 2015. Attitudes and perceptions of fishermen on the island of Ireland towards the development of marine renewable energy projects. Marince Policy Vol. 58 pp. 88-97.

Sanchez, Eunice Perez., Muir, James F. 2003. Fishermen perception on resources management and aquaculture development in the Mecoacan estuary, Tabasco, Mexico. Ocean \& Coastal Management. Vol 46 (6-7) pp. 681-700. 